\title{
AIDS-Related Malignancies Working Group
}

National Cancer Institute

\section{Source}

National Cancer Institute. AIDS-Related Malignancies Working Group. NCI Thesaurus.

Code C19518.

Function: Provide a national scientific forum to identify research opportunities and to provide recommendations on research priorities, resource needs, and how best to address them across the range of issues in AIDS-related malignancies. 